\title{
Classifying Popular Songs: Possibilities and Challenges
}

\author{
Rodrigo De Santis* and Rosali Fernandez de Souza** \\ Brazilian Institute of Information in Science and Technology. \\ 455 Lauro Muller Street, 4th floor, 22290-160, Rio de Janeiro, Brazil, \\ *<rodrigo@aquelamusica.com.br>,**<rosali@ibict.br>
}

\begin{abstract}
Rodrigo De Santis is a Ph.D. student in information science at the Brazilian Institute of Science and Technology Information (IBICT) in a partnership with the Federal University of Rio de Janeiro (UFRJ). He has a master's degree in computer science from the Federal University of the State of Rio de Janeiro, with research focused on music information systems. He is a cultural producer and researcher of Brazilian music as well as the founder and head of the research project "Aquela Música!" ("That Music!") which aims to build a semantic database of Brazilian popular songs.
\end{abstract}

Rosali Fernandez de Souza is a head researcher at the Brazilian Institute of Science and Technology Information (IBICT) and professor of the post-graduate program in information science through the IBICT-UFRJ partnership. She received her bachelor's degree in library science and documentation at Santa Ursula University, Rio de Janeiro, with a specialisation in scientific documentation. She received her master's degree in information science from IBICT-UFRJ and her doctorate from the Polytechnic of North London / CNAA, England. Her teaching and research area is knowledge organization.

De Santis, Rodrigo and Souza, Rosali Fernandez de. Classifying Popular Songs: Possibilities and Challenges. Knowledge Organization. 41(2), 181-187. 33 references.

Abstract: Classifying complex artistic objects, such as popular songs, raises important issues to knowledge organization studies. Historically, the popular song has been classified as a subcategory of other musical objects. However, recent researches show that the popular song is a specific artistic form that is endowed with its own language and, therefore, demands specific techniques for analysis, representation and, consequently, classification. Considering the different approaches toward popular songs in catalogues and contemporary systems, this paper identifies possible solutions, such as the use of descriptive metadata, the use of collaborative tagging or the creation of an ontology. In discussing the construction of an epistemological foundation used specifically for classifying the popular song, we reflect on the remaining challenges for the knowledge organization of complex artistic documents.

Received 1 August 2013; Accepted 1 August 2013

Keywords: popular song, musical classification, information, document, categories

\subsection{Popular Song}

'What is a popular song?' is a question difficult to answer. Despite its importance as a cultural product in contemporary society, only from the late 1990s, the popular song began to be systematically considered as an object of study by scientific field (Nestrovski 2007). This lack of reflection on the popular song can be attributed, for the most part, to its conceptual imprecision. Studies intending to define the popular song are rare. In the majority of
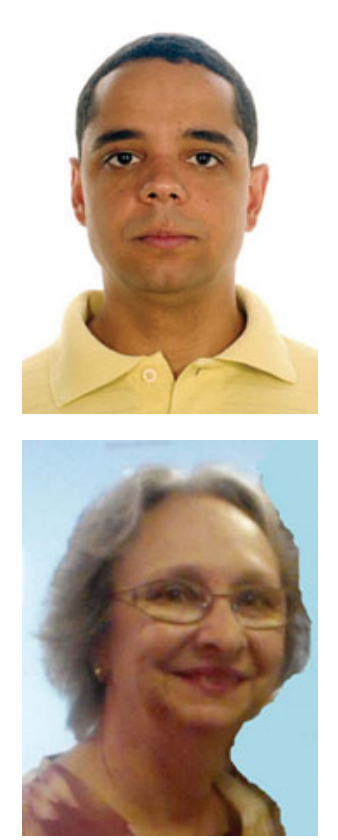
approaches, the current view still holds the popular song as a kind of music made from a literary text, in which case the music is usually singled out so that the texts- that is, the song lyrics — can be used in a textual analysis (Moore 2003). A third meaning is found in studies that use the popular song as an example, although they do not study it specifically, as often occurs in library and information science. In such cases, the popular song is usually synonymous with popular music, or even music in general, and often the terms are used interchangeably (Bradley 2003).

In a fundamental study of historical musicology, Mariz $(1977,26)$ asserts that the origin of the concept of song: "Goes back to remote antiquity and would have begun with a special form of onomatopoeia. When Greek civilization was still crawling and writing did not exist, they sang in honour of the gods .... The most primitive popular songs seem to have sprung from liturgical melodies." Mariz reveals at least two fundamental pieces of information. First, the origin of the song is the popular song rather than the classical song. Second, the song emerged spontaneously even before the emergence of writing. Recent studies, apparently taking other paths, arrived at the same conclusion: the popular song is a specific kind of object, not only for its precedence in relation to other musical or literary forms, but mainly because it has its own language (Tatit 1994).

\subsection{The language of the popular song}

The popular song, therefore, is born from the inflection of the voice. The same voice that speaks can be used to sing, and the music of popular song is born from this inflection process. The text-what is said by the voice-is born alongside this process, mixed with the music. This fundamentally differentiates the popular song from the classical song. In the classical song the music is created from a literary text, usually poetic, where both music and text are independent at the moment of their conception and obey their own respective rules-musical and literarydepending on the composer's ability to shape them.

In the popular song, however, the mixture of voice and song — of text and music_-does not follow pre-established rules, creating its typical instability. Considering these instabilities to be characteristics rather than defects is crucial in the attempt to understand popular song, seek appropriate tools of analysis and, in the specific case of this work, think of satisfactory forms of organization and classification. Although the distinction between popular song and classical song can be established through language, the distinction between popular music and classical music (and among folk music) is a more controversial and polemic discussion. These concepts have tenuous boundaries, which are socially constructed and more related to con- sumption markets than to the actual practice of these forms of artistic expression. Discussing these boundaries is beyond the interest of this paper. For the scope of this study, it is sufficient to define the popular song as an object of study endowed with its own language, thus constituting a specific domain which encompasses compositions made from the spontaneous practice of the voice inflections and whose primary purpose is to be sung.

\subsection{The complexity and variety of the aspects involved}

Tatit (1994) designated the language belonging to the popular song as a syncretic language. This syncretism results from the mixture and integration of the verbal with the musical, as well as the ability that song language acquires to express simultaneously a multiplicity of aspects, which ultimately characterises the popular song as a complex artistic object. The musical aspects (e.g. melody, harmony, and rhythm), the narrative aspects (i.e. the story that the song tells), the discursive aspects (i.e. how it is told), and the social and historical aspects (inherent in a cultural expression) do not alone compose the knowledge in a popular song.

According to Morin (1997, 2-3 emphasis added) this is precisely the greatest difficulty in studying complex objects: the risk of falling back into:

Partitioned, compartmentalized, monodisciplinary, quantified way of thinking [that] is opposed to true knowledge or the act of knowing, which must be based on contextualization, in a continuous spiral, in which there are movements to separate in order to analyse, and to reconnect in order to synthesize or become complex.

Therefore, although it is possible to extract aspects from a popular song and study them in isolated disciplines, this should not be the ultimate goal in studies dealing with complex objects. It is necessary to consider the rules and procedures governing the integration (rewiring) of these aspects in order to establish the popular song as a unit of knowledge to be analysed, represented and organised in its totality.

\subsection{Describing the Documents of Popular Songs}

From the moment they began to be represented through a written symbolic language and, much later, through sound recordings, popular songs began producing documents: respectively, scores and records. One of the oldest known song documents is the 'primitive score' of the Hurrian Hymn, a composition written in ancient Mesopotamia approximately 3400 years ago (Kilmer 1971). The word "hymn" in the title of this work is revealing 
because it shows that, from the beginning, there was concern about determining the type or function of songs and thus establishing a way of classifying the documents that were produced around them. Although there was this intuitive concern for classifying the artistic documents that were produced, the descriptions assigned to popular songs documents over the centuries were made on an ad hoc basis. Only in the twentieth century, with the consolidation of mass culture industries over the marketplace of popular culture production, has popular songunderstood as one of the most lucrative cultural products-become the object of a more objective standardisation. The category chosen for standardisation was the musical genre. The goal was to classify based on the consumers instead of the works themselves in order to lower the commercial risks of music industry in the marketplace (Santini 2010).

\subsection{The use of metadata}

More recently, libraries with music departments and institutions housing music collections have encountered the problem of describing and cataloguing documents related to musical works. In general, institutions that deal only (or primarily) with musical documents emphasise the creation of their own metadata model. Already, libraries and institutions that deal with other types of documents — such as books, newspapers, images, and so ontypically adopt a more general cataloguing standard, usually MARC (Machine-Readable Cataloging), and seek to accommodate the songs' specific information in the fields provided by this standard.

In a prior paper, we demonstrated the practical difficulties arising from describing musical features in both approaches, and we discussed the maintenance, retrieval, and interoperability problems they entail (De Santis and Lanzelotte 2013). Other works have discussed the adaptation (Hemmasi 2002) or even the creation of description standards for musical resources (Smiraglia 1997). For the popular song specifically, few descriptive metadata coincide with those usually employed for cataloguing other types of documents, such as title, author, and creation date. The other information from a song is usually disregarded or else clustered into a single descriptor: the musical genre.

\subsection{The 'musical genre' in classical musicology}

The use of the 'musical genre' concept is directly related to classical music (Mariz 1977). In this kind of music, it is possible to identify a work's fundamental characteristics with relative accuracy: from the combination of elements such as instrumentation (which instruments are frequently used), function (e.g. mass, prelude, or dance), and structure (e.g. linear, segmented, or repetitive). In the case of the classical song, it is still possible to categorise the type of poetic text that is being set to music (e.g. sacred, profane, romantic, etc.). More recently, especially following the atonality of Schoenberg in the early twentieth century and the emergence of electroacoustic music, classical music is also in need of a more comprehensive and flexible form of description (Wisnik 1989), which has always been a necessity in the case of the popular song.

\section{3. 'Musical genre' for the popular song}

Unlike what traditionally occurred in classical music, the constitutive elements of the popular song have always been inherently unstable and, in practice, a taxonomy with few genres is not able to provide information about its instrumentation, function, or structure. The arising of meaning effects produced by popular songs occurs by the mixture of their constitutive elements. These mixtures do not comply with pre-established rules, since the popular songs are built from the instability caused by the inflection of the voice and the syncretisation of music and lyrics. This explains the ad hoc descriptions and multiple terminologies seen in the attempts to describe the musical genre of popular songs from their most primitive origins. However, following mass culture industries' redefining and simplifying the musical genres of popular songs, new, more standardised and more controlled designations emerged. Yet, these designations say little to nothing about the content they are linked with for marketing reasons, such as 'World Music' or 'Latin Music', for example.

Even the musical genres that have historically stayed the same, such as blues, rock, or samba, are ambiguous with regard to their borders. The result is the inevitable unfolding of subgenres, which again shows the multiplicity of free definitions. According to Holt (2007), blues has over 40 identified subgenres: piano blues, acid blues, boogie-woogie, country blues etc. Rock has over 100: heavy metal, pop rock, garage rock etc. Along with these, samba, according to Severiano (2008), has more than 50 (bossa nova, pagode, samba-enredo etc.). Such ambiguity indicates that a set of descriptive metadata and a musical genre category are insufficient when describing popular songs, representing knowledge, and building a classification mechanism for this type of artistic document.

\subsection{The Classification of Popular Songs: Possibilities}

DiMaggio $(1987,411)$ points out the need to investigate different approaches to classification within cultural systems: "Unlike Sorokin, Marxists, and mass-culture theorists, I do not regard cultural systems as classifiable into discrete types, but view them as varying along several 
analytically distinct dimensions." Since the 1990s, several theoretical and technological developments have converged with DiMaggio's vision, creating new possibilities for the multidimensional classification of complex artistic documents.

The advent of the web as well as consumer market transformations since the end of the twentieth century resulted in profound changes for the popular songs market. With the creation and proliferation of digital formats and the decline in record sales, the music industry began to abandon the idea of music as a product in order to treat it as information and service (DiMaggio et al. 2001). This paradigm shift has fundamental implications for the classification of popular songs. Since the creation of 78RPM records in the second half of the nineteenth century, popular songs were recorded in groups. A 78-RPM album usually contained two songs (one on side A and the other on side B). At the end of the 1940s, with the invention of the long-play (LP), this capacity increased, and records started including more songs. With the invention of the compact disc (CD) in the 1980s, there was another increase in storage capacity.

With this development, the classification of artistic works using the category of musical genre also faced changes. If one initially sought to classify a song individually, with the emergence of albums, songs were classified by their grouping (a rock album, for example) or, in many cases, by artists themselves (an album by Nat King Cole, a jazz singer, for example). However, the creation and propagation of independent digital formats in the 1990sthe most common being the mp3 (MPEG-1/2 Audio Layer 3) - and web distribution overturned this system. The individual song once again became the unit rather than the album or artist. Since then, market demand has shifted sharply toward retrieval and recommendation services of these individual units and no longer to the sale of physical discs. This shift from a commercial perspective has confirmed a need that has already been identified from an artistic viewpoint: considering the popular song as a complex information document, defining organization models, and building classification and retrieval systems that take into account its multiple dimensions.

\subsection{Collaborative tagging}

One transformation caused by the mp3 format is that the users themselves are able to describe their musical files using the 'ID3 tag' format. This tag accompanies each mp3 file and provides a set of metadata similar to that used by libraries: title, artist, album, year, comment, and genre. The genre field usually allows selection from a predefined list of 80 musical genres, or the user is free to type in a new musical genre. The sharing of $\mathrm{mp} 3$ files and the subsequent construction of applications that search for and index songs using ID3 tags was one of the first collaborative tagging initiatives. With the technologies of web 2.0, music site users are now able to apply custom tags directly onto resources shared on the web rather than in their personal files. This allows for enormous databases of popular song documents that are described collaboratively, as in the case of the online radio services, such as Last.Fm (www.last.fm).

Various studies have analysed the use of tags in collaborative music classification systems (Aucouturier and Pampalk 2008; Thompson 2008; Lamere 2008; and Santini 2010). These studies suggest that collaborative tagging reveals categories that are not covered by conventional metadata, such as ratings by mood (e.g. calm, energetic, dark, or positive), personal opinions (e.g. cool, boring, like, or dislike), or suitable places to listen to the song (e.g. at a party, during dinner, or while jogging). On the other hand, these studies also reveal that the number of tags created by users tends toward infinity, as the adoption of a noncontrolled vocabulary ends up indefinitely multiplying the assignment of new tags. Another finding points to the difficulty in the practical use of tags during information search and retrieval. Since they are not hierarchical, in most cases user-created tags are not understood by other users. These studies also indicate that, although the quantity of tags grows indefinitely, there is a tendency to concentrate the use of a small set of tags on a small set of objects. In practice, the more well-known songs receive many similar classifications, while most of the songs have no classification, leading to deviations and a tendency toward massification in the recommendations made by this kind of computer systems. If there is an undeniable gain from the creation of new ways to classify songs beyond musical genre and metadata, the problem lies once again in the absence of more specific criteria for defining categories to describe effectively the content of popular songs.

\subsection{Semiotic perspective}

French semiotics from the Paris School, beginning with the studies of Algirdas Julien Greimas, its founder, has historically been used to analyse literary and artistic documents. The influence of the phenomenological view on this mind-set has been in addressing the need for a pragmatic approach to artistic classification. In understanding the emergence of the meaning effects as a phenomenological action and, therefore, of a partial and continuous character, semiotics establishes criteria to study complex thinking in keeping with Morin's views, namely, that the complexity of knowledge is achieved from fragments, analysis, and the 'rewiring' of knowledge. 
The first formulations of the Paris School of Semiotics, fundamentally structuralist, served as the basis for the later formulations, which were more flexible and sensitive, according to the term used by Greimas himself in his last work (Greimas and Fontanille 1991). Currently, mainly from developments in "tensive semiotics"-Fontanille and Zilberberg 1998; Zilberberg 2002; and Zilberberg 2006the systematisation of a category analysis that is sensitive to rhythm, variations, and tones offers a theoretical foundation to define gradual and continuous categories. This has been applied to different types of artistic documents, such as in the fine arts (Costantini 2010), poetry (Sturnack 2011), and also the popular song (Tatit 2002).

Musicovery (www.musicovery.com), an online radio application, adopts gradual categories to reflect the mood of different musical aspects of the recordings offered to its users. In addition to traditional categories, such as musical genre, or a search by metadata, such as recording year or composer name, the users can search for songs using a matrix that situates them in a space according to two axes: calm or energetic, and dark or positive. Gradation, or the possibility to reflect intensity within categories, is one possibility to replace the discrete types that were criticised by DiMaggio in 1987. Although it was not possible to identify whether there is some theoretical basis for the Musicovery site's construction and use of these gradual categories, it is interesting to note that the apparent reflections of collaborative ratings, coupled with advances in computer technology, now offer paths toward a change in conventional forms of information cataloguing and retrieval.

\subsection{The semiotics of song}

The study of rhythms, variations, and tones proposed by tensive semiotics found the popular song to be a prototypical object of study. The applicability of the model to various dimensions of popular songs has been developed in recent years from the initial studies of the relationships between melody and lyrics proposed by Tatit (1994). The semiotics of song has been found to be a possible methodology in determining the most appropriate categories to describe the information in a popular song. For example, the aforementioned unevenness of melodic structure common to the popular song, which is caused by the instability of the singing voice, can be described through the semiotic category of 'melodic profile.' Defined by the intrinsic relationship between tempo, duration, and syllabic division, the melodic profile allows the inconsistencies and recurrences of melodic utterances in popular songs to be represented gradually.

The construction of a classification system that considers this type of analytical approach must therefore consider not only fragments of musical data (in the previous example, tempo, duration, and syllabic division), but also the complex system of dependencies and rules governing relations among these fragments. This form of representation cannot be reached through the use of thesauri or classification tables, but it has shown promise when presented in an ontology, where one can explicitly define the rules and each type of relationship (Gnoli, Bosch and Mazzocchi 2007).

\subsection{Fragmented data and ontology-based systems}

In a previous work, the project "That Music!" (a free translation from "Aquela Música" - the original title in Portuguese), we discussed using an ontology to build an application grounded on the analysis of popular songs that consider aspects of semiotic theory (De Santis 2013). The project received its name from its initial intention, which was to answer the question routinely asked when trying to remember or discover a song for which one has little or fragmented information: "What's That Song? - the one that talks about that subject, the one sung by that particular singer, or with that specific musician playing the flute," for example.

Based on the recognition of the fragments that make up popular songs and the relationships among them, the project aims to map appropriate categories for this type of document. The fragments are both descriptive metadata (title, composer, instrument, recording year, etc.) as well as a song's objective data (tone, mode, tempo, etc.). Derivative categories, such as modalization and instrumental formation are identified from the relationships between these concepts. The recurrence of relationships, derived from the mixtures of fragments and categories, allows the identification of rules governing the formation of more complex categories, which map characteristics of an unstable nature, such as, for example, the melodic profile above mentioned. As a representation of the multidimensional view of complex thinking, through the prototype 'That Music!' (www.aquelamusica.com.br), the user can begin to navigate from any category or any song fragment, using it as a filter. With the application of logical rules, the program calculates which songs cater more accurately to the filters used, reproducing the path to reconstruct songs from the fragments, in order to answer the question 'What's That Song?', which was formulated in the origin of the project.

\section{The Classification of Popular Songs: Challenges}

The new perspectives on classifying popular songs presented in the previous section certainly do not exhaust all the possibilities, nor do they explore all ongoing initia- 
tives. Collaborative classification, analytical models based on semiotic theory, and ontology-based systems complement the use of traditional metadata and the category of musical genre. They are also a point of view theoretically coherent and comprehensive, and promising in terms of building applications for classifying artistic documents within the current technological scene. However, it is important to realise that these approaches bring with them new challenges and also confirm prior concerns that remain unresolved.

\subsection{Operationalization}

A major challenge, especially when considering large volumes of data such as the collections of songs on the web, is the operationalization of classification. In this sense, computer science has used increasingly more efficient algorithms for automatic cataloguing, as in the case of applications that recognise melodic patterns or are able to classify sound frequencies based on mathematical models. Proposals like 'Musicovery', while satisfactory for music in general, do not solve the specific problem of popular song analysis, which depends on deeper analyses and the application of non-automated knowledge, as is the case of the semiotic analysis of songs. Initiatives such as 'That Music!' confirm this limitation: the cost of manual analysis is very high, and describing each fragment and the logical rules in large amounts of data are not feasible. On the other hand, the collaborative classification proposal, operationalized by the end-users themselves, shows promise. To be applied broadly, however, it is necessary to solve the problem of a lack of semantics in uncontrolled vocabularies, and the massification tendencies of these classifications.

\subsection{Information retrieval}

In the area of music information, a specific research group, ISMIR (International Society for Music Information Retrieval), has met annually since 2000 to discuss specific issues and challenges. Initially, their emphasis was on studies related to automatic retrieval, algorithms, and computational systems. In recent years, the group has sought a more interdisciplinary approach and invested in studies to construct conceptual bases for music information retrieval (Downie et al. 2010).

Langridge (1992), when addressing classification and identifying types, elements, systems, and applications, noted that each individual (or group of individuals) can construct his or her own system for classifying information. The problem, however, lies in information retrieval. If each individual or group establishes its own criteria for classification, it is not feasible to retrieve information in a standardised way. According to Saracevic (1975), the con- cept linking classification to retrieval is relevance. In every application considered in this work, including the prototype "That Music!", the descriptive metadata and the category of musical genre are always present. Inarguably, these dimensions are relevant to the classification of artistic documents. The challenge remaining, and one which may become even more difficult in the face of the many possibilities offered by technological advances, is to identify which categories are relevant to describing popular songs and to determine the best way to classify data in these categories, keeping retrieval in mind.

\subsection{Final Considerations}

Reflecting on the need to consider the language of the popular song, the inadequacy of traditional descriptive models for complex artistic documents became clear. It is necessary, then, to adopt a more comprehensive model than the functionalist view that is predominantly used in the classification of other types of documents. Ever mindful of the remaining challenges, we direct these final thoughts toward a reflection on the role of the knowledge organization studies. The research considering the popular song as a scientific object is still in the incipient stage. The need for classification to depart from epistemological determinations and explicit cultural foundations and trends (Hjørland 2004) reaffirms the significance of knowledge organization as the science able to promote, through its interdisciplinary nature, the integration of analytical and philosophical contributions from semiotic theory and technological solutions derived from computer science.

\section{References}

Aucouturier, Jean-Julien and Pampalk, Elias. 2008. Introduction-from genres to tags: a little epistemology of music information retrieval research. Journal of new music research 37: 87-92.

Bradley, Carol June. 2003. Classifying and cataloguing music in American libraries: a historical overview. Cataloging \& classification quarterly 35 no.3/4: 467-81.

Cook, Nicholas. 1994. A guide to musical analysis. Oxford University Press.

Costantini, Michel. 2010. La sémiotique visuelle: nouveaux paradigmes. Vol. 1. Paris: Harmattan.

De Santis, Rodrigo. 2013. Knowledge organization and the conceptual basis for building classification systems for complex documents: an application on the Brazilian popular song domain. In Franch, Xavier and Soffer, Pnina, eds., Advanced information systems engineering workshops, CAiSE 2013 International Workshops, Valencia, Spain, June 17-21, 2013, Proceedings. Berlin Heidelberg: Springer, pp. 349-60. 
De Santis, Rodrigo and Lanzelotte, Rosana. 2013. Difusão de partituras através da web: o desafio de tornar acessíveis os repertórios brasileiros. In Goldberg, Luiz Guilherme D., Santos, Luis Otávio S. and Valverde, Rodolfo V., eds., Intertextualidades: fronteiras entre o sacro e o profano na música do Brasil colonial e imperial - IX Encontro de Musicologia Histórica. Centro cultural Pró-Música. Universidade Federal de Juiz de Fora.

DiMaggio, Paul. 1987. Classification in art. American sociological review 52: 440-55.

DiMaggio, Paul, Hargittai, Eszter, Neuman, W. Russell and Robinson, John P. 2001. Social implications of the Internet. Annual review of sociology 27: 307-36.

Downie, J. Stephen, Ehmann, Andreas F., Bay Mert and Jones, M. Cameron. 2010. The music information retrieval evaluation exchange: some observations and insights. In Raś, Zbigniew and Wieczorkowska, Alicja A, eds., Advances in music information retrieval, Berlin Heidelberg: Springer, pp. 93-115.

Fontanille, Jacques and Zilberberg, Claude. 1998. Tension et signification. Sprimont: Mardaga.

Gnoli, Claudio, Bosch, Mela and Mazzocchi, Fulvio. 2007. A new relation for multidisciplinary knowledge organization systems: dependence. In Alvite-Díez, María Luisa and Rodríguez-Bravo, Blanca, eds., Interdisciplinarity and transdisciplinarity in the organization of scientific knowledge, proceedings of the Eighth ISKO-Spain Conference. León, Spain; Universidad de León, Secretariado de Publicaciones, pp. 399-409.

Greimas, Algirdas Julien and Fontanille, Jacques. 1991. Sémiotique des passions: des états de choses aux états d'âme. Paris: Editions du Seuil.

Hemmasi, Harriette. 2002. Why not MARC? In International Conference on Music Information Retrieval - ISMIR, pp. 242-48.

Hjørland, Birger. 2004. Arguments for philosophical realism in library and information science. Library trends 52 no. 3: 488-506.

Holt, Fabian. 2007. Genre in popular music. Chicago: University of Chicago Press.

Kilmer, Anne Draffkorn. 1971. The discovery of an ancient Mesopotamian theory of music. Proceedings of the American Philosophical Society 115 n.2: 131-49.

Lamere, Paul. 2008. Social tagging and music information retrieval. Journal of new music research 37: 101-14.
Langridge, Derek Wilton. 1992. Classification: its kinds, elements, systems and applications. London: Bowker-Saur.

Mariz, Vasco. 1977. A canção brasileira. Rio de Janeiro: Civilização Brasileira.

Moore, Allan F. 2003. Analysing popular music. Cambridge: Cambridge University Press.

Morin, Edgar. 1997. Réforme de pensée, transdisciplinarité, réforme de l'Université. In Congrès International Quelle Université pour demain (Locarno, Suisse, 30 avril - 2 mai 1997). Motivation 24. Available http://ciret-trans disciplinarity.org/bulletin/b12c1.php

Nestrovski, Arthur Rosenblat. 2007. Lendo música: 10 ensaios sobre 10 canções. São Paulo: Publifolha.

Santini, Rose Marie. 2010. Os usuários e a desorganização da cultura: Os Sistemas de Recomendação e as conseqüências da classificação para os usos sociais da música na Internet. Ph.D. dissertation. Niterói: Universidade Federal Fluminense.

Saracevic, Tefko. 1975. Relevance. A review of and a framework for the thinking on the notion in information science. Journal of the American Society for Information Science 26: 321-43.

Severiano, Jairo. 2008. Uma história da música popular brasileira: das origens à modernidade. São Paulo: Editora 34.

Smiraglia, Richard P. 1997. Describing music materials: a manual for descriptive cataloging of printed and recorded music, music videos, and archival music collections: for use with AACR2 and APPM. Lake Crystal, Minn.: Soldier Creek Press.

Sturnack, Lionel. 2011. Claude Zilberberg, Cheminements du poème. Baudelaire, Rimbaud, Valery, Jouve. Semen. Revue de sémio-linguistique des textes et discours 32: 189-92.

Tatit, Luiz. 1994. Semiótica da canção: melodia e letra. São Paulo: Escuta.

Tatit, Luiz. 2002 Analysing popular songs. In Hesmondhalgh, David and Negus, Keith, eds., Popular music studies. London, Arnold, pp. 33-50.

Thompson, Abbey E. 2008. Playing tag: an analysis of vocabulary patterns and relationships within a popular music folksonomy. Chapel Hill, North Caroline: University of North Carolina.

Wisnik, José Miguel. 1989. O som e o sentido: uma outra bistória das músicas. São Paulo: Companhia das Letras.

Zilberberg, Claude. 2002. Précis de grammaire tensive. Tangence 70: 111-143.

Zilberberg, Claude. 2006. Éléments de grammaire tensive. Limoges: Pulim. 